\title{
O paradoxo do território e os processos de estigmatização no acesso ao diagnóstico de HIV na atenção básica em saúde
}

Gustavo Zambenedetti. Universidade Estadual do Centro-Oeste

Rosane Azevedo Neves da Silva. Universidade Federal do Rio Grande do Sul

\section{Resumo}

Diretrizes políticas recentes têm preconizado a efetivação de processos de descentralização do acesso ao diagnóstico de HIV. Através do acompanhamento de um projeto de descentralização no município de Porto Alegre-RS, este artigo propõe uma análise da dimensão paradoxal do território e dos processos de estigmatização no acesso ao diagnóstico de HIV no contexto da Atenção Básica em Saúde. A abordagem teórico-metodológica foi fundamentada na perspectiva analítico-institucional e as estratégias metodológicas envolveram observações, grupos-focais e entrevistas com profissionais de uma Unidade de Saúde da Família, usuários do sistema de saúde, profissional de uma equipe de matriciamento e gestor municipal da política de DST-Aids. A análise evidencia a dimensão paradoxal do território e suas implicações para as práticas profissionais e as políticas públicas. Apresenta, por fim, a noção de multiterritórios como um dos modos de pensar múltiplas possibilidades de acesso ao diagnóstico de HIV.

Palavras-chave: HIV, Aids, estigma, atenção primária à saúde, análise institucional.

\begin{abstract}
The paradox of the territory and the stigmatization processes regarding access to HIV diagnosis in Primary Health Care. Recent policy guidelines have supported the completion of the decentralization processes regarding the access to HIV diagnosis. Through follow-up of a decentralization project in the city of Porto Alegre-RS, this study proposes an analysis of the paradoxical dimension of the territory and of the processes of stigmatization regarding access to the HIV diagnosis in the context of Primary Health Care. The theoretical and methodological approach was founded on the analytical and institutional perspective and the methodological strategies involved observation, focal groups and interviews with professionals of a Family Health Unit, users of the health care system, a professional of the matrix support team, and a manager of the STD-Aids policies in the city. Analysis evidence the paradoxical dimension of the territory and its implications regarding the professional practices and public policies. Finally, it presents the notion of multiterritories as a way to conceive multiple possibilities of access to HIV diagnosis.
\end{abstract}

Keywords: HIV, AIDS, stigma, primary health care, institutional analysis.

\section{Resumen}

La paradoja del territorio y los procesos de estigmatización en el acceso al diagnóstico de VIH en Atención Primaria de Salud. Directrices políticas recientes han recomendado la ejecución de los procesos de descentralización del acceso al diagnóstico de SIDA. Mediante lo acompañamiento de un proyecto de descentralización en Porto Alegre-RS, este artículo propone un análisis de la dimensión paradójica de lo territorio y el proceso de estigmatización el acceso al diagnóstico del VIH en el contexto de la atención primaria de salud. El enfoque teórico y metodológico se basó en la perspectiva analítica e institucional y las estrategias metodológicas incluyen observaciones, grupos focales y entrevistas con los profesionales de una Unidad de Salud de la Familia, los usuarios del sistema de salud, profesional de un equipo de orientación especializada y administrador de la política de las ETS y el SIDA. El análisis pone de relieve la dimensión paradójica del territorio y de sus implicaciones para las prácticas profesionales y de política pública. Presenta, por último, la noción de multiterritórios como una de las formas de pensar múltiples posibilidades de acceso al diagnóstico de VIH.

Palabras clave: VIH, SIDA, estigma, atención primaria de salud, análisis institucional. 
Porto Alegre-RS tem sido destaque por ser considerada a capital brasileira com a maior taxa de incidência de Aids (Brasil, 2013). Enquanto a taxa de incidência de Aids no Brasil, em 2013, foi de 20,2/100 mil habitantes, em Porto Alegre foi de 93,7/100 mil habitantes, chegando a mais de 200/100 mil habitantes em algumas regiões da cidade (Stella, Qualisoni, \& Moisyn, 2011). Os dados encontrados em Brasil (2013) indicam ainda elevada taxa de transmissão vertical ${ }^{1}$ e de mortalidade por Aids no município. Uma das hipóteses consideradas por gestores e profissionais de saúde é a de que a resposta do sistema de saúde esteja aquém do esperado (Andrade, 2011), exigindo novas estratégias de enfrentamento à epidemia. Diante deste cenário, a Secretaria Municipal de Saúde de Porto Alegre propôs, em 2011, um projeto de descentralização da atenção em HIV-Aids para a Atenção Básica - AB. Deve-se considerar que já existia um indicativo político da necessidade de a $A B$ realizar ações de prevenção, assim como de aconselhamento pré-teste e de encaminhamento para a realização do diagnóstico em serviços especializados ou em laboratórios conveniados com as Secretarias Municipais de Saúde (Brasil, 2003, 2006). Os processos de descentralização operariam uma reconfiguração destas ações, através da realização do diagnóstico dentro das unidades de saúde, responsabilizando as suas equipes pela comunicação do diagnóstico, solicitação de exames complementares e pelo cuidado e acompanhamento das Pessoas Vivendo com HIV-Aids - reconhecidas sob a sigla PVHA - assintomáticas.

A proposta de descentralização em nível local encontra ressonância em outros municípios e estados brasileiros, estando em consonância com diretrizes nacionais bastante recentes (Brasil, 2014). Em 2012 foi publicada a portaria $n^{\circ} 77$ (Brasil, 2012), que dispõe sobre a oferta do teste rápido de HIV, sífilis e hepatites virais pelas unidades de $A B$ no âmbito da atenção pré-natal. Apesar de preconizar a oferta destes testes às gestantes e seus parceiros sexuais, a portaria também sugere a possibilidade de expansão da oferta para a população em geral, a critério das gestões municipais.

A Estratégia Saúde da Família - ESF é um dos componentes da $A B$ e possui papel estratégico na estruturação do SUS por constituir-se como articuladora dos pontos da rede de atenção. Sua expansão é bastante expressiva nas duas últimas décadas no Brasil: em janeiro do ano 2000 havia 4.428 equipes, passando para 33.100 em $2013^{2}$. A noção de território emerge como importante operador da Política Nacional de Atenção
Básica (Brasil, 2011), especialmente nos tópicos que abordam as especificidades da ESF. Preconiza-se que a ESF realize uma definição precisa do seu território de atuação através do processo de territorialização, que consiste em um mapeamento e reconhecimento da área adscrita, cadastramento das famílias e indivíduos e reconhecimento das características sociais, econômicas, culturais, demográficas e epidemiológicas do território. Segundo os fundamentos e diretrizes da $A B$, o território adscrito permite o planejamento, programação descentralizada e desenvolvimento de ações setoriais e intersetoriais (Brasil, 2011).

Há um pressuposto embutido nesta política de que a proximidade com o território facilita o acesso da população ao serviço, assim como possibilita à equipe uma ação mais contextualizada. No entanto, autores como Ferreira Neto (2011) inserem uma via de problematização acerca da noção de território presente em muitas políticas públicas. Segundo o autor, "quando as políticas sociais territoriais são implementadas pelo poder público, um aparato regulamentador e de controle passa a decidir sobre sua configuração, na medida em que as demarcações territoriais obedecem também a critérios administrativos, desconsiderando muitas vezes aspectos socioculturais locais" (2011, p. 65).

Em relação à atenção em HIV-Aids, argumentamos que o território pode assumir um significado paradoxal, principalmente em decorrência do estigma associado à Aids. O estigma pode ser definido como uma marca que desqualifica o indivíduo perante os demais (Goffman, 2008). Ele não se constitui apenas como um atributo individual, mas como um processo ligado à reprodução de iniquidades e de exclusão (Parker \& Aggleton, 2003). A experiência do estigma relacionado à Aids é relatada em artigos e documentos internacionais (Garcia \& Koyama, 2008; Garrido et al, 2007; ONUSIDA, 2005; UNAIDS, 2008), evidenciando seu impacto em diferentes contextos. A percepção de que nem sempre a proximidade territorial facilita o acesso ao diagnóstico e tratamento para HIV-Aids teve início na experiência profissional de um dos autores do presente artigo, enquanto psicólogo residente ${ }^{3}$ de um serviço de âmbito estadual, localizado no município de Porto Alegre-RS, que sedia um Centro de Testagem e Aconselhamento (CTA ${ }^{4}$ e a Clínica de HIV-Aids ${ }^{5}$. Através dos atendimentos realizados foi possível constatar que alguns usuários deslocavam-se de outros municípios na busca de assistência, apesar da existência de serviços similares em seus municípios de origem. Como expressão dessa situação, relatamos 
um atendimento no qual a aconselhadora pergunta ao usuário "qual é seu município", tendo como resposta "Viamão", município da região metropolitana de Porto Alegre. A aconselhadora pergunta: "você sabe que pode fazer esse teste em Viamão, que lá também tem um CTA?", obtendo como resposta: "Sim, mas prefiro vir aqui". Em outro momento, em um atendimento psicoterápico, uma PVHA relata que buscou a unidade básica de saúde de sua região em decorrência de uma dor abdominal. A médica da unidade solicitou a realização de um exame anti-HIV. Porém, o usuário sabia de seu diagnóstico, mas não queria revela-lo na unidade de saúde, alegando ser conhecido na cidade e temer que o sigilo em relação ao seu diagnóstico não fosse mantido. Ele passou então a interrogar: como justificar para a médica a não realização do exame? Deveria deixar de frequentar a unidade para garantir o sigilo? O que chama a atenção, neste último relato, é o fato de a revelação do diagnóstico na unidade de saúde produzir tensão na relação entre usuário e profissional de saúde. Essas experiências no campo da assistência convocaram à realização de pesquisas visando à produção de conhecimento na área. Nesse sentido, um estudo foi conduzido em 2009 (Zambenedetti \& Both, 2012, 2013), em período anterior à proposta de descentralização no município de Porto Alegre, tendo como objetivo compreender a percepção de profissionais de equipes da ESF sobre a atenção em HIV-Aids e a relação com o estigma. Foi constatada a existência de uma dimensão paradoxal do território, expressa na afirmação de uma Agente Comunitária de Saúde (ACS) de que "a via que facilita é a mesma que dificulta". O estudo identificou que os ACS ocupavam uma dupla função enunciativa na relação com os moradores do território, fazendo com que ora fossem vistos como profissionais, ressaltando o aspecto ético de seu trabalho; ora fossem reconhecidos como vizinhos, constrangendo sua atuação. Nesse sentido, a proximidade territorial poderia tanto auxiliar quanto dificultar a atuação, aspecto reforçado por outros profissionais da ESF.

Esses achados encontraram correlações na literatura. UNAIDS (2008) afirma que um dos efeitos do estigma relacionado à Aids pode ser o deslocamento para fora da comunidade local na busca de atenção, pelo temor da difusão de dados confidenciais. Almeida e Labronici (2007) estudaram os aspectos que motivaram algumas pessoas com HIV a não procurarem serviços do SUS para realizarem o acompanhamento de sua saúde. A partir das entrevistas realizadas, constataram que há um receio na procura por serviços próximos ao local de moradia dessas pessoas, pelo medo de serem identificadas ou de encontrarem pessoas conhecidas. Seone e Fortes (2009) investigaram a percepção de usuários de equipes de ESF sobre o sigilo e a confidencialidade das informações. Os resultados indicaram que a preocupação com o sigilo e a confidencialidade das informações não está presente em todos os casos, a não ser quando envolve alguns diagnósticos específicos, entre os quais o de HIV.

A proposição de um processo de descentralização da atenção em HIV-Aids no município de Porto Alegre, a partir de 2011, reativa uma controvérsia: até que ponto haveria adesão dos usuários às ações propostas na atenção básica em saúde, visto que a proximidade com o território pode tanto facilitar quanto dificultar o acesso? Como essa dimensão paradoxal se expressa no processo de descentralização? Nesse sentido, nosso interesse se direciona a continuidade do estudo da interface entre as ações em HIV-Aids e a AB, porém em um novo contexto, relacionado ao processo de descentralização. É importante destacar que a explicitação da experiência profissional e de pesquisa de um dos autores possibilita colocar em evidência aquilo que convoca a pensar sobre esse tema, remetendo à análise de implicação, compreendida como um exercício de compreensão dos pertencimentos e das posições ocupadas nas relações sociais. Essa análise expressa a impossibilidade de neutralidade na relação entre pesquisador e pesquisa (Lourau, 1993).

Neste contexto, o presente artigo decorre de um recorte analítico de uma tese de doutorado (Zambenedetti, 2014) e delimita uma via de problematização bastante específica, tomando as relações entre estigma e território no transcurso de um processo de descentralização do cuidado em HIV-Aids para a AB.

Haesbaert (2009) afirma que a noção de território vem sendo apropriada por várias áreas de conhecimento ao longo da segunda metade do século $X X$, não se restringindo a um conceito da geografia, mas transitando pela economia, ciências sociais, antropologia, sociologia e psicologia. O território passa a ser concebido como expressão de relações de poder, através das quais é possível delimitar, esquadrinhar, constituir segmentações e (des)apropriações, operando dinâmicas que podem facilitar ou dificultar o fluxo de informações, comunicação e pessoas. A relação entre os modos de vida da população e a gestão pública da rede de saúde orientada pela noção de território, assim como as convergências e divergências em torno deste debate, constituem o foco principal da presente análise. 


\section{Método}

A perspectiva teórico-metodológica que orientou este estudo foi a analítico-institucional. 0 institucionalismo é caracterizado como um movimento que agrega diferentes correntes de pensamento, entre as quais destacamos a análise institucional ou sócio-análise, que tem como expoentes René Lourau e Georges Lapassade, e a esquizoanálise ou filosofia da diferença, que tem como expoentes Félix Guattari e Gilles Deleuze. Agrega, ainda, contribuições de autores como Erving Goffman e Michel Foucault, os quais, apesar de não serem considerados institucionalistas, trouxeram importantes contribuições para a compreensão, análise e construção de ferramentas de análise do campo institucional.

L'Abbate (2013) afirma que a análise institucional pode oferecer importante instrumental para a análise de objetos da saúde coletiva. Guizardi, Lopes e Cunha (2011) afirmam que a análise institucional auxilia na compreensão e análise de políticas públicas que apresentam aspectos inovadores. Segundo os autores, mesmo com desenhos inovadores, algumas políticas de saúde acabam mantendo, na prática cotidiana dos serviços, certas orientações que a própria política buscava combater. A análise institucional, através de suas ferramentas conceituais, auxilia justamente a identificar processos de permanência, assim como processos de ruptura de determinados instituídos. A pesquisa-intervenção serve como uma das orientações desta pesquisa, sendo compreendida por Rocha e Aguiar (2003) como um dispositivo de transformação da realidade, tendo como perspectiva interrogar os múltiplos sentidos cristalizados nas instituições. Ela se constitui como ação desnaturalizadora, colocando em análise os efeitos das práticas no cotidiano do trabalho em saúde. Nesta pesquisa, tomamos o território como uma noção instituída no âmbito das políticas de saúde, as quais ressaltam a relação entre proximidade territorial e facilidade no acesso do usuário à unidade de saúde, desconsiderando outros aspectos que podem interferir nesta relação.

A pesquisa abordou quatro grupos distintos de sujeitos envolvidos no processo de descentralização: trabalhadores de uma equipe de ESF e de uma equipe de matriciamento das ações em HIV-Aids; gestor da política municipal de DST-Aids; usuários que buscaram o diagnóstico de HIV em uma unidade de ESF e usuários que foram diagnosticados com HIV nesta unidade.
Deve-se pontuar que, em revisão bibliográfica acerca da descentralização da atenção em HIV-Aids, realizada na base Scielo e Lilacs, não foram encontrados registros de estudos envolvendo o cruzamento destes diferentes segmentos de participantes (Zambenedetti, 2014). Consideramos que esse cruzamento é relevante por colocar em diálogo as percepções de sujeitos que se encontram em diferentes posições dentro do processo, representando os que planejam (gestores), os que executam (trabalhadores) e os que usam (usuários) o Sistema Único de Saúde. Essas divisões tendem a colocar em campos distintos o pensamento e a ação, o planejamento e a execução, resultando em processos de burocratização. Guirado (1987, p, 34) menciona a afirmação de Georges Lapassade de que a burocracia constitui-se como a "organização da separação". Uma das intenções da análise institucional é romper com essa lógica, religando pensamento e ação, planejamento e execução, justificando o cruzamento realizado em nossa pesquisa.

A unidade de ESF participante da pesquisa atua na região geográfica que possui a maior taxa de incidência de Aids em Porto Alegre, justificando sua escolha para o início do projeto de descentralização (Stella et al, 2011). A unidade de saúde selecionada foi uma das que realizou o maior número de testes rápidos de HIV desde a implantação do projeto de descentralização, sendo composta por três equipes de ESF, totalizando: três médicos, três enfermeiros, seis técnicos de enfermagem, cerca de 15 Agentes Comunitários de Saúde - ACS, além dos profissionais responsáveis pela recepção, administrativo e segurança.

A pesquisa foi aprovada pelos Comitês de Ética em Pesquisa do Instituto de Psicologia da Universidade Federal do Rio Grande do Sul e da Secretaria Municipal de Saúde de Porto Alegre. A participação teve caráter voluntário e ocorreu mediante a leitura e assinatura do Termo de Consentimento Livre e Esclarecido - TCLE.

Propusemos a realização de um grupo focal com os profissionais de nível superior (médicos, enfermeiros, dentista); um grupo focal com técnicos de enfermagem; um grupo focal com os ACS. Os profissionais também permitiram a observação de suas atuações durante as sessões de aconselhamento pré-teste coletivo, realizadas na unidade de ESF, além de auxiliarem na captação de usuários e no acompanhamento do pesquisador e apresentação do chamado "território adscrito" à unidade de saúde. 
A constituição dos grupos focais levou em consideração o critério de homogeneidade (categorias profissionais), número de participantes e espaço físico disponível para a sua realização. Cada grupo teve de cinco a oito participantes. Diferentemente da entrevista, os grupos focais possibilitam apreender percepções, sentimentos, opiniões em situação de interação (Trad, 2009). Neste sentido, constitui-se como um dispositivo de intervenção, pois propõe a reflexão sobre o assunto tomado como foco, propiciando o compartilhamento e revisão de opiniões através da explicitação semiestruturada de convergências e divergências.

A entrevista constitui-se como a forma de participação do representante da gestão da Política Municipal de DST-Aids, do profissional da equipe de matriciamento que se constitui como referência para a Unidade de ESF; e dos usuários que acessaram a unidade de saúde para fazer o teste rápido de HIV. Trinta e um usuários que realizaram o teste rápido na unidade de saúde foram convidados a participar da pesquisa, dos quais dezenove aceitaram o convite. Entre eles, 15 eram mulheres (nove gestantes) e quatro eram homens.

Também foram realizados dois encontros de restituição, reunindo todos os profissionais das equipes de ESF. Coimbra, Scheinvar, Ayres e Nascimento (2005) afirmam que "a restituição é um procedimento intrínseco à pesquisa visto ser um dispositivo que permite à população pesquisada escapar do lugar instituído de objeto e ao pesquisador sair da posição de neutralidade instituída como científica" (p. 133-134). Nestes dois encontros houve a apresentação da sistematização inicial dos dados produzidos na pesquisa, disparando discussões na equipe. A restituição atendeu também a uma demanda da equipe, relacionada ao conhecimento da opinião dos usuários sobre os serviços ofertados na unidade. Apesar da demanda de pesquisa partir inicialmente do pesquisador, foi possível observar a emergência de demandas por parte dos participantes, considerando que "as demandas surgem gradualmente com o avançar do trabalho, elas são produzidas por todos os envolvidos no trabalho socioanalítico" (Monceau, 2013, p. 95). O cruzamento dos dados proporcionado na restituição possibilitou a ampliação da análise por parte das equipes.

Neste artigo, propomos analisar a relação entre território e processos de estigmatização da Aids no acesso ao diagnóstico na $A B$. Delimitamos três linhas analíticas no tocante a esta temática. A primeira aborda as convergências entre a proposta política e a percepção da população, gestores e equipes de saúde. A segunda aborda algumas divergências nessa relação, produzindo uma dimensão paradoxal no acesso ao diagnóstico de HIV. A terceira evidencia três modos distintos de operar a relação com o território, abrindo a discussão sobre a noção de multiterritórios, indicando contribuições para o campo em análise.

\section{Caracterização da inserção do diagnóstico de HIV na unidade de saúde}

A equipe delimitou a sexta-feira, no turno da tarde, para a realização da ação de diagnóstico de HIV e sífilis. O agendamento era realizado ao longo da semana na recepção da unidade, nas consultas com os profissionais da equipe ou através do contato com os ACS. Em cada turno poderiam ser agendadas até oito pessoas. Os usuários eram orientados a comparecer na unidade às $13 \mathrm{~h}$, momento em que eram direcionados a uma sala de grupos para a realização do aconselhamento pré-teste coletivo, que consiste em uma ação que visa abordar aspectos informativos/educativos, aspectos emocionais, além da avaliação de riscos (Brasil, 2003). Essa ação tinha duração de 20 a 30 minutos. Posteriormente, conforme a ordem de chegada à unidade, os usuários eram encaminhados para um consultório, onde era realizado o teste rápido e o aconselhamento pós-teste individual. Essa ação era realizada por enfermeiros e médicos-residentes, os quais possuíam uma escala de revezamento semanal. Enquanto o aconselhamento coletivo veiculava informações mais gerais, no momento de realização do teste e aconselhamento pós-teste individual era possível aos usuários expor dúvidas mais pessoais, assim como as motivações para a realização do diagnóstico. Foi observado que, eventualmente, o teste também era realizado em outros turnos, durante atendimentos ou consultas de enfermagem.

\section{Convergências}

Nesta linha, abordamos três aspectos presentes nas entrevistas com os 19 usuários que realizaram o aconselhamento e teste-rápido de HIV na ESF e que evidenciam convergências entre a proposta política e a percepção dos usuários. O primeiro se refere ao modo pelo qual os usuários souberam que o teste era realizado na unidade de saúde; o segundo diz respeito ao motivo que os levaram a fazer o teste; e o terceiro se relaciona com a percepção sobre a ação do aconselhamento/teste. 
Em relação ao motivo para a realização do teste: nove mulheres indicam ter realizado o teste em função do encaminhamento no pré-natal; sete usuários identificaram práticas de risco relacionadas à relação sexual sem preservativo; um usuário relatou motivos médicos (anemia) que o levaram a fazer o exame; um usuário relatou a indicação médica, pois a esposa estava grávida. Também identificou o que considerava ser uma prática de risco - ter usado o "prestobarba" do sobrinho, o qual era "suspeito" de ter HIV; uma das usuárias soube que o ex-companheiro está hospitalizado com Aids. Os excertos abaixo evidenciam o que os usuários identificam como "práticas de risco" que os levaram a buscar a realização do diagnóstico:

Eu sou feio, né cara, mas eu falo bastante com as gurias, ai fica mais fácil levar um monte de mulher para a cama, né. E esses dias tive uma palestra de uma doutora no serviço sobre a Aids e fiquei meio pensativo: "bah, o que eu to fazendo transando sem camisinha?". Ai eu vim aqui fazer o [teste] rápido, né. (Us. 9).

E eu também me arrisco muito, sou muito sincera em dizer isso: eu me arrisco. (Us. 1).

Apesar de o público-alvo prioritário da ação ser constituído por gestantes e seus parceiros, conforme orientação da portaria $n^{\circ} 77 / 2012$ (Brasil, 2012), observa-se a adesão de outros segmentos populacionais ao teste, aspecto também destacado pela equipe, pelo matriciamento e pela gestão. Em relação ao usuário que relacionou o "uso do prestobarba" ao risco para a infecção pelo HIV, foi importante o trabalho da equipe em desconstruir tal relação, assim como discutir o estigma que pode levar as pessoas a separarem objetos e terem comportamentos de segregação diante da suspeita de alguém com HIV.

Em relação ao aconselhamento/realização do teste na unidade de ESF, a maioria dos entrevistados ressaltou aspectos considerados positivos, tais como: o acesso à informação (mencionado em cerca de 10 entrevistas)/"conversa" (três entrevistas), o conforto/ apoio emocional (duas entrevistas), o resultado sair na hora (cinco entrevistas), por ser no posto e não precisar deslocamento (duas entrevistas).

A proximidade da unidade em relação às residências é um aspecto que facilita o acesso para a realização do teste-rápido de HIV, sendo mencionado por alguns usuários o fato de não ser necessário a utilização de transporte público:
Porque a verdade é que a gente não sai daqui para fazer nada, só se for uma coisa muito necessária. Ir por ir ali para fazer o teste, como teve no $1^{\circ} \mathrm{de}$ dezembro, tu não sai. Ai tendo no posto de saúde tu sabe que é pertinho de casa, tu vem e tu faz. (Us. 5).

Tanto entre o representante da gestão quanto entre a equipe de ESF houve a afirmação de que o acesso ao teste é ampliado, principalmente para a população de baixa renda, que tem maior dificuldade para efetivar o deslocamento até um serviço especializado.

Muitos usuários referiram já ter informações sobre HIV-Aids, mas mesmo assim consideraram importante a prática do aconselhamento. $O$ componente informativo/educativo presente no aconselhamento tem importante impacto sobre a redução do estigma, pois os mitos e fantasias relacionados às formas de infecção pelo HIV constituem-se como importante componente dos processos de estigmatização. O acesso a informações corretas constitui-se como uma potente estratégia de desconstrução de estigmas, evitando comportamentos discriminatórios (Garcia \& Koyama, 2008; UNAIDS, 2008).

A agilidade na devolução do resultado do teste também foi destacada, principalmente pelos participantes que já haviam realizado o teste anteriormente e puderam "comparar" a modalidade do teste-rápido com o método tradicional: "A diferença é que é rápido, é prático, tu só vai ali e fura o dedo. É rapidinho." (Us. 3). O teste rápido tem a execução, leitura e interpretação dos resultados em até 30 minutos, enquanto a entrega dos resultados dos testes laboratoriais convencionais pode levar, em média, entre 10 e 15 dias. O Ministério da Saúde indica que a demora na entrega do resultado pode contribuir para a desistência da busca pelo resultado (Brasil, 2008).

Foi apontada também a percepção de que o modo como a ação é desenvolvida possibilita que qualquer pessoa possa ir até a unidade de saúde e ter acesso a ela, denotando uma espécie de "democratização", conforme o relato a seguir: "Uma coisa que a minha família que passou pra mim, quer dizer que qualquer outro da comunidade pode ir passando para pessoas que não sabem". (Us. 12).

Neste sentido, evidencia-se a convergência entre as formas de divulgação da ação, a percepção de um motivo para a realização do teste e a avaliação de que o modo como a ação é realizada vem ao encontro das expectativas dos usuários. A equipe relatou a existência de um receio anterior à implementação do processo: de que ninguém procuraria o teste na unidade em decorrência do estigma relacionado à Aids. Por esse 
motivo, desenvolveram ações de sensibilização e divulgação da oferta do teste para a comunidade: conversas do Conselho Local de Saúde e das ACS com a população local, distribuição de informativos sobre a realização do teste, afixação de cartazes indicando dia e horário para a realização do teste de HIV na unidade de saúde. Fica evidente, neste contexto, que a demanda de realização do teste por parte da população não está colocada de antemão, sendo modulada pela oferta da ação, ressaltando o pressuposto institucionalista de que as demandas não são naturais, mas sim produzidas (Baremblitt, 1996). O trabalho de divulgação realizado pela unidade de saúde cria, junto à população, a demanda de realização do teste. Outro aspecto a ser considerado é que o território-zona delimita uma visibilidade em relação à prevenção e ao diagnóstico de HIV, constituindo uma das condições para a efetivação da relação intensiva de produção de saúde. Haesbaert (2009) define o território-zona como um território espacial, com delimitação clara de fronteiras e a respectiva percepção de dentro-fora, definindo uma noção de pertencimento, semelhante à delimitação operada pelas equipes de ESF.

Por outro lado, encontramos também aspectos dissonantes na relação entre oferta da ação diagnóstica pela unidade de saúde e a população, os quais serão abordados a seguir.

\section{Divergências: A constituição da dimensão paradoxal}

Apesar da ampliação do acesso, isso não significa que algumas tensões não surjam em momentos relacionados ao processo de realização do aconselhamento e teste rápido de HIV. Uma das participantes relatou ter se sentido constrangida e envergonhada no momento em que ocorreu a "chamada" dos usuários na sala de espera da unidade:

Ah, para mim foi muito difícil, já não achei legal (...) chamar "quem vai fazer o teste rápido?". Puxa vida! Eu achei que ia poder chegar no balcão e mostrar que eu ia fazer o teste rápido, né. E ele(a) fez uma divulgação, que a minha filha disse assim "vai mãe, é tu" e eu disse "não". Bah, tinha um monte de gente conhecida ali, fiquei bem constrangida. (...) "[me senti] envergonhada de fazer o teste... não porque eu to aqui, mas assim pelo modo que [o/a profissional] abordou "quem vai fazer o teste rápido?". Que eu pensei que chegava ali no balcão e [alguém] nos encaminhava. Ah, eu fiquei muito constrangida e minha filha "ah, que vergonha". Daí ela disse "mostra o papel", daí tive que mostrar. (...) ah eu assim, não é preconceito de ninguém, que eu vejo, mas poderia chamar no balcão. Tu já está agendada, então é só marcar tua presença, fulana veio, e não precisar dizer (Us. 16).

A continuação do relato da usuária demonstra que a realização do teste pode ser permeada pelo estigma, pois designa a possibilidade de estar com HIV, colocando a pessoa (morador da área adscrita) em dúvida perante a comunidade:

Porque vai que eu não to [com HIV]? Mas eu já fiz o teste, que o pessoal que estava ali, tinha bastante gente conhecida, que eu moro aqui, nasci e me criei no morro. (...) eu não vou sair com uma placa na cabeça dizendo "eu não sou reagente" (risos). Para provar para aquelas pessoas ali, que vai se espalhar o boato, "ah, filha do fulano ta lá no postinho fazendo teste de HIV, com medo que tenha contraído" (Us. 16).

Essa passagem remete à afirmação de Goffman (2008): "as pessoas íntimas podem tornar-se aquelas em relação às quais ele [o portador do estigma] mais se preocupa em esconder algo vergonhoso" (p. 64). Desse modo, expressa uma relação entre a familiaridade com as pessoas da comunidade e a preocupação com a privacidade e o sigilo. Outra usuária confirma esse aspecto ao mencionar ter encontrado pessoas conhecidas durante a realização do diagnóstico de HIV: "Todo mundo meio que se conhece! Porque tu mora numa comunidade. Eu vou na igreja ali na esquina. Tem mais uns três ou quatro que vão" (Us. 19).

Através destes relatos é possível compreender que a demanda do usuário pelo diagnóstico é acompanhada por outras demandas, relacionadas ao sigilo e privacidade, como já indicado em outros estudos (Abdala \& Nichiata, 2008; Ferreira \& Nichiata, 2008). Estes relatos enunciam o discurso moral, relacionado ao "o que irão pensar de mim", que evidencia a ideia de que o HIV estaria associado a algo imoral, errado ou a algum desvio que desvaloriza algumas pessoas perante outras, atualizando o dispositivo da sexualidade, articulado ao processo de estigmatização. O dispositivo, na perspectiva foucaultiana, é constituído por uma engrenagem de elementos heterogêneos, envolvendo saberes, relações de poder, conjuntos de regras e normas que posicionam os sujeitos nas relações sociais, atribuindo valores a estes sujeitos e às suas ações (Foucault, 1988). Esse processo constitui-se também como uma forma de hierarquizar os sujeitos conforme suas ações, podendo resultar em formas de discriminação, ou seja, formas de tratamento consideradas desiguais e injustas. 
Foi observado, ainda, que a gestação é um dos aspectos que interfere na representação de gênero, conforme demonstra este relato:

Porque pensa assim: eu tô grávida, mas e outros que não estão, e o cara que não está, que é homem, ai vão pensar: "ah, o fulano foi lá no posto fazer teste de HIV, será que está com Aids? (Us. 19).

As representações de gênero relacionam-se à compreensão do que é ser homem ou mulher em uma sociedade. Segundo Louro (2008), "a construção dos gêneros e das sexualidades se dá através de inúmeras aprendizagens e práticas, insinua-se nas mais distintas situações, é empreendida de modo explícito ou dissimulado por um conjunto inesgotável de instâncias sociais e culturais" ( $p$. 18). Nesse sentido, a representação compartilhada na situação anterior equivale à absolvição da gestante perante a realização do teste e a de desconfiança perante a muIher não gestante ou aos homens, sobre os quais podem incidir julgamentos morais. Este modo de representação também pode levar à simplificação ou não realização do aconselhamento para as gestantes, como indicado por Souza, Santo e Motta (2008). Para evitar a identificação e possível julgamento das pessoas que fazem o teste, uma usuária sugeriu que o acesso ao diagnóstico:

podia ser uma coisa mais reservada, assim. Para ficar mais legal, porque já ficou legal fazer o teste no posto, sai o resultado na hora. Mas podia ser mais reservado. Acho que na hora que for ali pode chamar como se fosse uma consulta (Us. 19).

Os relatos destas usuárias foram apresentados para a equipe na restituição da pesquisa, a qual demonstrou surpresa e discutiu a necessidade de desvincular o momento da sala de espera - no qual fazem a divulgação da oferta do teste rápido na unidade de saúde - do momento de chamada dos usuários agendados para a realização do teste rápido. Assim, poderiam garantir maior privacidade aos usuários agendados. A restituição constitui-se como um dos momentos privilegiados de intervenção dentro da perspectiva teórico-metodológica do presente estudo. As falas das usuárias sensibilizaram a equipe para a produção de mudanças no processo de trabalho, afirmando o comprometimento da pesquisa-intervenção com a ampliação da capacidade analítica e de transformação dos grupos.

Se o tópico anterior demonstrou a existência de situações que indicam a ampliação do acesso, este tópico indica que esta ampliação não ocorre sem tensões, ressaltando o caráter paradoxal do território.
Deleuze (1974) traz importantes contribuições para a compreensão da noção de paradoxo. Segundo o autor, o paradoxo remete a um contrassenso, mas que não equivale a uma ausência de sentido. Pelo contrário, trata-se de um excesso de sentido, em decorrência da possibilidade de que um 'e' outro existam, como um par que oscila, colocando ênfase ora em um ora em outro dos efeitos. O paradoxo se constitui de modo distinto do "bom senso". O bom-senso, segundo Deleuze (1974), efetua uma distribuição fixa ou sedentária: "ele é o senso-único, exprime a existência de uma ordem de acordo com a qual é preciso escolher uma direção e se fixar a ela" (p. 78). Corresponde ao modo pelo qual o território é muitas vezes inserido no contexto das políticas públicas, afirmando um único sentido. Por outro lado, Deleuze (1974) afirma que a "potência do paradoxo não consiste absolutamente em seguir a outra direção, mas em mostrar que o sentido toma sempre os dois sentidos ao mesmo tempo, as duas direções ao mesmo tempo" (p. 79).

É importante distinguir a noção de paradoxo da noção de contradição. A contradição envolve dois sentidos contrários, que seguem caminhos excludentes, exigindo uma escolha por um dos polos. Por outro lado, a noção de paradoxo, ao veicular a coexistência de vias distintas, indica não a necessidade de resolução ou escolha de um dos polos, mas sim, a necessidade de habitar o paradoxo, como afirma Deleuze (1974). Isso requer acompanhar os seus efeitos, ocupar-se dele. A partir dessa perspectiva, a questão deixa de ser "descentralizar ou não descentralizar a atenção em HIVAids" e passa a ser "como buscar formas de qualificar as ações de descentralização, lidando com uma dimensão paradoxal que é constitutiva de tal processo?"

Pensamos que o paradoxo nos auxilia a compreender que o acesso do usuário à $A B$ não exclui a estigmatização. Ao contrário, posiciona o usuário em relações de tensionamento perante o elemento que facilita (a proximidade) e o elemento que constrange (a familiaridade, a vizinhança).

\section{Da fixação à flexibilização e interrogação: a afirmação dos multiterritórios}

Diante da existência de uma dimensão paradoxal do território, considera-se a demanda de alguns usuários pelo acesso a serviços que não estejam localizados próximos ao seu local de moradia. Diante de tal demanda, endereçada às equipes de saúde, observamos a constituição de três respostas distintas, as quais 
denominaremos de fixação, flexibilização e interrogação. Elas evidenciam diferentes modos de constituir a relação dos usuários e equipes de saúde com o território, conforme apresentamos a seguir.

A primeira perspectiva, denominada de fixação, é caracterizada pela compreensão de que os usuários que residem em áreas cobertas por unidades de Saúde da Família devem necessariamente realizar o diagnóstico e acompanhamento nestas unidades. Segundo o representante da gestão, essa perspectiva é recente, sendo expressa no relato de:

Um caso em que a equipe trocou a usuária de território para a busca de leite de fórmula láctea de crianças. (...). Nós vamos chamar a equipe aqui para discutir. Porque a ideia seria nós convencermos essa família a fazer a retirada [na sua unidade de referência]. Ai a família ia dizer assim "ah, mas eu vou sair com as latas de leite e todo mundo vai perceber que eu não tô amamentando". Bom, então nós temos que forjar uma situação que permita a essa mulher continuar ali. Enfim, mandando entregar o leite em casa pela ACS. Alguma coisa tem que ser feita, mas não trocar de território (Representante da gestão).

Ao utilizar técnicas de esquadrinhamento do espaço para fixação ao território, essa perspectiva tensiona profissionais e usuários a adequarem-se ao desenho proposto pela gestão.

A segunda perspectiva é a de flexibilização, caracterizada pela compreensão de que caberia ao usuário decidir qual é o local mais propício para o acesso ao diagnóstico ou tratamento, considerando-se que:

O problema não é a equipe manter o sigilo, o problema é a pessoa se sentir a vontade. Porque a gente já tem tantos fatores para acabar com o envolvimento dele com o tratamento, tu botar mais um? Não vejo necessidade (Matriciamento).

Diferentemente da perspectiva anterior, toma como referência a escolha do usuário. Estudo realizado por Palácio, Figueiredo, \& Souza (2012) junto a usuários de uma unidade especializada no cuidado de doenças infecciosas identificou que a escolha do local para a realização do "cuidado em saúde se dá de acordo com as facilidades de acesso próprio de cada um, não necessariamente sendo a distância entre seu domicílio e o serviço um critério determinante destas facilidades" (p. 364). Para Cecílio (2004), nem sempre o local indicado pelo sistema de saúde coincide como o melhor local segundo a percepção dos usuários. Nesse sentido, o usuário acessa o sistema por onde ele considera melhor, fazendo do sistema um círculo ou rede, com múltiplos pontos de entrada.

A terceira perspectiva, denominada de "interrogação", parte de um pressuposto distinto: deve-se interrogar o sujeito e buscar compreender quais são os aspectos que intervêm na sua escolha em relação ao serviço, conforme a passagem a seguir: "E qual é o elemento que a pessoa que vive com a Aids identifica, naquela comunidade, para dizer que ali não vai ter resguardo do sigilo da situação dela? Por que ela identifica isso? Por ser vista na unidade?" (representante da gestão). A partir disso, busca-se estabelecer um diálogo entre as demandas do usuário e as possibilidades de organização do sistema. Nesta última perspectiva, as decisões sobre o local mais adequado de acesso ao diagnóstico ou tratamento não são tomadas a priori, mas sim, discutidas com o usuário, levando-se em consideração os diversos aspectos que podem influenciar sua escolha. Ao mesmo tempo, as equipes também são interrogadas em seu fazer, colocando em análise a sua implicação com a possibilidade de mudança do usuário de território: Isso designaria uma desresponsabilização da equipe perante o caso? Haveria alternativas? Ela se constitui como uma força instituinte, pois interroga aspectos instituídos não apenas em relação aos usuários, mas também sobre as equipes de saúde e a lógica de organização do sistema.

As duas últimas perspectivas possibilitam a abertura para a compreensão acerca das múltiplas possibilidades de habitar um território, dentro de uma perspectiva multiterritorial. Ao analisar as formas de vida contemporânea, Haesbaert (2009) afirma que as pessoas têm constituído novas formas de relação com o território. Estas relações envolvem não necessariamente a fixação em um determinado espaço, mas a possibilidade de circular e territorializar-se de diversas maneiras. O território não se torna menos importante hoje do que foi em outras épocas, mas passa a ser apropriado através de novas lógicas e possibilidades. É dentro desta perspectiva que consideramos o processo de descentralização do diagnóstico de HIV para a AB: ele deve representar uma ampliação das possibilidades de acesso, sem necessariamente barrar as possibilidades de acesso e/ou fluxo para outros serviços.

Ao analisar uma epidemia complexa e com múltiplas estratificações deve-se buscar a afirmação de uma perspectiva de multiterritorialidade, oferecendo diversas possibilidades de pontos de entrada para o acesso ao diagnóstico, exames e tratamentos. Consideramos 
que seja um risco entender a descentralização apenas como um deslocamento ou transferência das ações dos serviços especializados para a $\mathrm{AB}$, se esse deslocamento tiver uma expectativa de substituição, através do qual os serviços especializados deixariam de existir ou perderiam sua função. $A A B$ não pode ser vista como panaceia, por enfrentar problemas estruturais, entre os quais poderíamos citar a baixa cobertura em algumas regiões do país, o modelo ainda presente das Unidades Básicas de Saúde-UBS tradicionais em detrimento das equipes de ESF, a rotatividade de profissionais, a baixa incorporação de tecnologias de cuidado específicas em algumas áreas como HIV-Aids. Nesse sentido, a mudança extensiva das ações deve ser acompanhada por uma mudança intensiva, relativa à abordagem do problema. Haesbaert (2009), ao apresentar a multiterritorialidade, refere-se à possibilidade de habitar diferentes territórios, alguns com características mais zonais, outros com características mais reticulares. Em um mundo dinâmico e com novas possibilidades de relacionar-se com o tempo e o espaço, torna-se cada vez mais presente a ligação dos territórios em redes, os quais são muitas vezes descontínuos no espaço. Ou seja, é possível aos sujeitos estabelecerem relações não apenas com o que está mais próximo e delimitado espacialmente, mas com outros elementos, seja através de redes virtuais ou por condições tecnológicas, econômicas e culturais que possibilitam o deslocamento ágil e o acesso a determinados locais. Segundo o autor, no entanto, somos impelidos ou constrangidos, possibilitados ou impossibilitados de transitar ou ocupar esses múltiplos territórios, segundo condições muito específicas, perpassadas por aspectos culturais, assim como por aspectos econômicos que veiculam a possibilidade de acesso a bens e serviços, tendo sido destacado pelos participantes da pesquisa que "não precisar pegar um ônibus para descer o morro" é um facilitador do acesso. Por outro lado, ter a possibilidade de acesso a outros serviços considerados mais centrais também deve ser uma garantia no desenho das políticas de saúde.

\section{Considerações finais}

$A$ análise realizada permite indicar que a $A B$ se coloca como um novo território para o acesso ao diagnóstico de HIV. Nesse processo, foi possível identificar tanto convergências quanto divergências e tensionamentos entre as intenções das políticas públicas e os modos de vida da população. Entre as convergências, encontramos a ampliação do acesso ao diagnóstico e às ações de prevenção a uma população que passa a ter a possibilidade de acessar o diagnóstico em um serviço próximo de sua residência. Por outro lado, encontramos tensionamentos na relação com a dimensão do estigma e da sexualidade, dificultando ou constrangendo o acesso à unidade de saúde.

Esperamos, com o estudo realizado, contribuir para a análise de um processo em desenvolvimento no campo das políticas públicas, enfatizando a dimensão da interface da política com os sujeitos a ela relacionados. Argumentamos favoravelmente à possibilidade de constituição de multiterritórios para o acesso ao diagnóstico de HIV, devendo esta ampliação ser acompanhada pela qualificação das práticas profissionais, pautadas pelo respeito à diversidade, pelo direito à preservação da intimidade e sigilo das informações, além do respeito aos direitos humanos. A compreensão da dimensão paradoxal do território nos aproxima de uma perspectiva na qual se torna necessário habitar os paradoxos que constituem o processo de descentralização, buscando ocupar-se deles, em um constante processo de análise de seus efeitos e modos possíveis de resolução.

\section{Referências}

Abdala, F.T.M, \& Nichiata, L.Y.I. (2008). A abertura de privacidade e o sigilo das informações sobre o HIV/Aids das mulheres atendidas pelo Programa Saúde da Família no município de São Paulo, Brasil. Revista Saúde eSociedade, 17(2), 140-152. doi: 10.1590/S0104-12902008000200014

Almeida, M. R .C. B, \& Labronici, L. M. (2007). A trajetória silenciosa de pessoas portadoras do HIV contada pela história oral. Ciência \& Saúde Coletiva, 12(1), 263-274. doi: 10.1590/\$1413-81232007000100030

Andrade, G. (2011, 04 de dezembro). Casos de Aids põem o Estado em alerta. Jornal Correio do Povo, p. 17.

Baremblitt, G. F. (1996). Compêndio de análise institucional e outras correntes: teoria e prática. Rio de Janeiro: Rosa dos Tempos.

Brasil, Ministério da Saúde (2003). Aconselhamento em DST/HIV/Aids para a Atenção Básica. Brasília: Ministério da Saúde.

Brasil, Ministério da Saúde (2006). HIV/Aids, hepatites e outras DST / Cadernos de Atenção Básica, $n^{\circ} 18$ (Série A. Normas e Manuais Técnicos). Brasília: Ministério da Saúde.

Brasil, Ministério da Saúde (2008). Centros de testagem e aconseIhamento do Brasil: desafios para a equidade e o acesso. Brasília: Ministério da Saúde.

Brasil, Ministério da Saúde(2011). Portaria MS/GM no 2.488, de 21 de outubro de 2011. Aprova a Política Nacional de Atenção Básica, estabelecendo a revisão de diretrizes e normas para a organização da Atenção Básica, para a Estratégia Saúde da Família (ESF) e o Programa de Agentes Comunitários de Saúde (PACS).

Brasil, Ministério da Saúde (2012). Portaria no 77, de 12 de janeiro de 2012. Dispõe sobre a realização de testes rápidos, na Atenção Básica, para a detecção de HIV e sífilis, assim como testes rápidos para outros agravos, no âmbito da atenção pré-natal para gestantes e suas parcerias sexuais. 
Brasil, Ministério da Saúde (2013). Boletim Epidemiológico Aids - DST (Ano II, no 1). Brasília: Ministério da Saúde.

Brasil, Ministério da Saúde (2014). 5 passos para a implementação do manejo da infecção pelo HIV na Atenção Básica - guia para gestores. Brasília: Ministério da Saúde.

Cecílio, L. C.O. (2004). Modelos tecno-assistenciais em saúde: da pirâmide ao círculo, uma possibilidade a ser explorada. In Brasil, VER-SUS Brasil: caderno de textos (pp. 90-106). Brasília: Ministério da Saúde.

Coimbra, C. M. B., Scheinvar, E., Ayres, L. S. M., \& Nascimento, M. L. (2005). Pivetes: uma singular experimentação. Estudos e Pesquisas em Psicologia, 5(2), 130-135. Recuperado de http:// pepsic.bvsalud.org/scielo.php?script=sci_arttext\&pid=S1808$-42812005000200013 \&$ lng $=$ pt\&tlng=pt

Deleuze, G. (1974). Lógica do sentido. São Paulo: Perspectiva.

Ferreira, C. F., \& Nichiata, L. Y. I. (2008). Mulheres vivendo com Aids e os profissionais do Programa Saúde da Família: revelando o diagnóstico. Revista da Escola de Enfermagem (USP), 42(3), 480-486. doi: 10.1590/S0080-62342008000300010

Ferreira Neto, J. L. (2011). Psicologia, políticas públicas e o SUS. São Paulo: Escuta; Belo Horizonte: Fapemig.

Foucault, M. (1988). História da sexualidade - A vontade de saber (Vol. 1). Rio de Janeiro: Edições Graal.

Garcia, S, \& Koyama, M. A. H. (2008). Estigma, discriminação e HIV/ Aids no contexto brasileiro, 1998 e 2005. Revista de Saúde Pública, 42(3), 72-83. doi: 10.1590/S0034-89102008000800010

Garrido, P. B., Paiva, V., Nascimento, V. L. V., Sousa, J. B., \& Santos, N. J. S. (2007). Aids, estigma e desemprego: implicações para os serviços de saúde. Revista de Saúde Pública, 41(6), 72-79. doi: 10.1590/ S0034-89102007000900012

Goffman, E. (2008). Estigma - notas sobre a manipulação da identidade deteriorada (4를 ed.). Rio de Janeiro: LTC.

Guirado, M. (1987). Psicologia institucional. São Paulo: EPU.

Guizardi, F. L, Lopes, M. R., \& Cunha, M. L. S. (2011). Contribuições do Movimento Institucionalista para o estudo de políticas públicas de saúde. In R. A. Mattos \& T. W. F. Baptista (Orgs.), Caminhos para análise das políticas de saúde (pp. 200-218). Rio de Janeiro: Fiocruz.

Haesbaert, R. (2009). Do "fim dos territórios" à multiterritorialidade. Rio de Janeiro: Bertrand Brasil.

L'Abbate, S. (2013). Análise institucional e saúde coletiva: uma articulação em processo. In S. L'Abbate, L. C. Mourão, \& L. M. Pezzato (Orgs.), Análise institucional e saúde coletiva (pp. 31-90). São Paulo: Hucitec.

Lourau, R. (1993). Análise institucional e práticas de pesquisa. Rio de Janeiro: UERJ.

Louro, G. L. (2008). Gênero e sexualidade: pedagogias contemporâneas. Pro-Posições, 19(2), 17-23. doi: 10.1590/S010373072008000200003

Monceau, G. (2013). A socioclínica institucional para pesquisas em educação e em saúde. In S. L'Abbate, L. C. Mourão, \& L. M. Pezzato (Orgs.), Análise institucional e saúde coletiva (pp. 91-103). São Paulo: Hucitec.
ONUSIDA (2005). Violaciones de los derechos humanos, estigma y discriminación relacionados com el VIH: estúdios de caso de intervenciones exitosas. Ginebra: ONUSIDA.

Palácio, M. B., Figueiredo, M. A. C., \& Souza, L. B. (2012). O cuidado em HIV/Aids e a atenção primária em saúde: possibilidades de integração da assistência. Revista Psico (PUCRS), 43(3), 360-367. Recuperado de http://revistaseletronicas.pucrs.br/ojs/index.php/ revistapsico/article/view/9816

Parker, R., \& Aggleton, P. (2003). HIV/Aids-related estigma and discrimination: A conceptual framework and implications for action. Social Science \& Medicine, 57, 13-24. doi: 10.1016/S02779536(02)00304-0

Rocha, M. L., \& Aguiar, K. F. (2003). Pesquisa-intervenção e a produção de novas análises. Psicologia: Ciência e Profissão, 23(4), 64-73. doi: 10.1590/S1414-98932003000400010

Seoane, A. F., \& Fortes, P. A. C. (2009). A Percepção do usuário do programa aaúde da damília sobre a privacidade e a confidencialidade de suas informações. Revista Saúde e Sociedade, 18(1), 42-49. doi: 10.1590/S0104-12902009000100005

Sousa, M. C. P., Santo, A. C. G. E., \& Motta, S. K. A. (2008). Gênero, vulnerabilidade das mulheres ao HIV/Aids e ações de prevenção em bairro da periferia de Teresina, Piauí, Brasil. Revista Saúde e Sociedade, 17(2), 58-68. doi: 10.1590/S010412902008000200007

Stella, I. M., Qualisoni, C. M. D., \& Moisyn, D. C. (2011). Aids em Porto Alegre. Boletim Epidemiológico (Secretaria Municipal de Saúde de Porto Alegre), 13(45), 2-3. Recuperado de http://lproweb. procempa. com.br/pmpa/prefpoa/cgvs/usu_doc/10018-boletim_epidemiologico_setembro_2011_45[1].pdf

Trad, L. A. B. (2009). Grupos focais: conceitos, procedimentos e reflexões baseadas em experiências com o uso da técnica em pesquisas de saúde. Physis, 19(3), 777-796. doi: 10.1590/S010373312009000300013

UNAIDS (2008). Reducir el estigma y la discriminación por el VIH: una parte fundamental de los programas nacionales del sida - Recurso para las partes interesadas en la respuesta al VIH en los diferentes países. Ginebra: ONUSIDA.

Zambenedetti, G. (2014). O paradoxo do território e os processos de estigmatização da Aids na atenção básica em saúde (Tese de doutorado).Universidade Federal do Rio Grande do Sul, Porto Alegre. Recuperado de: http://www.lume.ufrgs.br/bitstream/handle/10183/115057/000956460.pdf?sequence=1

Zambenedetti, G., \& Both, N.S. (2012). Problematizando a atenção em HIV-Aids na Estratégia Saúde da Família. Polis e Psique, 2(1), 99-119. Recuperado de http://seer.ufrgs.br/PolisePsique/article/ view/30512

Zambenedetti, G, \& Both, N. S. (2013). "A via que facilita é a mesma que dificulta": estigma e atenção em HIV-Aids na Estratégia Saúde da Família - ESF. Fractal, 25(1), 41-58. doi: 10.1590/S198402922013000100004

\footnotetext{
${ }^{1}$ Trata-se da infecção pelo HIV passada da mãe para o filho, durante a gestação, no parto ou pelo aleitamento materno.

${ }^{2}$ Dados extraídos de consulta realizada no site do Departamento de Atenção Básica/Ministério da Saúde: http://dab.saude.gov.br/dab/historico_cobertura_ sf/historico_cobertura_sf_relatorio.php

${ }^{3}$ O Programa de Residência Integrada em Saúde constitui-se como uma modalidade de pós-graduação, baseada no ensino em serviço ao longo de 24 meses.

${ }^{4}$ Serviço destinado ao diagnóstico e aconselhamento em HIV-Aids e outras doenças sexualmente transmissíveis (DST), no âmbito do SUS.

${ }^{5}$ Serviço destinado ao tratamento das pessoas diagnosticadas com HIV, composto por equipe interdisciplinar.
} 
O paradoxo do território e os processos de estigmatização no acesso ao diagnóstico de HIV na atenção básica em saúde

Gustavo Zambenedetti, Doutor em Psicologia Social e Institucional pela Universidade Federal do Rio Grande do Sul (UFRGS), é Professor Adjunto do Departamento de Psicologia da Universidade Estadual do Centro-Oeste (Unicentro). Endereço para correspondência: Rua Frei Orlando, $n^{\circ} 52$, ap. 41. Centro.

Irati-PR. CEP: 84500-000. E-mail: gugazam@yahoo.com.br

Rosane Azevedo Neves da Silva, Doutora em Educação pela Universidade Federal do Rio Grande do Sul (UFRGS), é Professora do Instituto de Psicologia e do Programa de Pós-Graduação em Psicologia Social e Institucional da Universidade Federal do Rio Grande do Sul (UFRGS). E-mail: rosane.neves@ufrgs.br 